\title{
Antioxidant activities of purified glycoprotein extracted from Codium decorticatum
}

\author{
Dharmaraj Senthilkumar, Sivaraman Jayanthi* \\ Plant Biotechnology Division School of Bio Sciences and Technology VIT University Vellore - 632014 Tamil Nadu, India.
}

\begin{tabular}{|c|c|}
\hline ARTICLE INFO & ABSTRACT \\
\hline $\begin{array}{l}\text { Article history: } \\
\text { Received on: } 05 / 11 / 2015 \\
\text { Revised on: } 30 / 11 / 2015 \\
\text { Accepted on: } 14 / 12 / 2015 \\
\text { Available online: } 27 / 12 / 2015\end{array}$ & $\begin{array}{l}\text { Marine algae are known to produce an extensive variety of bioactive metabolites and several novel drugs have } \\
\text { been derived for the pharmaceutical industries. However glycoproteins from the algae have not been adequately } \\
\text { explored for their potential as a source of bioactive substances. The objectives of this study were to investigate } \\
\text { the antioxidant activity effect of glycoprotein (GLP). In the experiment of the radical elimination ability by } \\
\text { means of 1,1-diphenyl-2-picryhydrazyl (DPPH) expressed anti-oxidative effect depending on the concentration }\end{array}$ \\
\hline $\begin{array}{l}\text { Key words: } \\
\text { Glycoprotein; Antioxidant } \\
\text { activity; Green algae; DPPH; } \\
\text { Reducing power; Codium } \\
\text { decorticatum. }\end{array}$ & $\begin{array}{l}\text { showed that antioxidant abilities in the dose depended concentration. These results express that GLP eliminates } \\
\text { GLP can be used to new material of food supplements related to antioxidants. }\end{array}$ \\
\hline
\end{tabular}

\section{INTRODUCTION}

Seaweed contains diverse biological activity in potential medicinal value, such as anticoagulant, antiangiogenic, anti-inflammatory, antitumor, antiviral, and antioxidant (Athukorala et al., 2007; Dias et al., 2005; Chang et al., 2008; Zhu et al., 2006; Zhou et al., 2008). Generally all the organisms are capable to defense antioxidant and repair oxidative damage in the systems that develop, as these systems are unable to prevent the damage entirely. Antioxidants can prevent or delay the oxidizable substrates in the cell. Generally this mechanism in two ways: ROS scavenging and inhibiting the generation of ROS. Food processing industries are using some synthetic antioxidant compounds. However, the alternative natural antioxidant from available biological sources and interest of extensive finding has arisen. In the recent years, seaweeds crude extracts, secondary metabolites, polysaccharides have been demonstrated to be potential ROS scavengers. Nowadays there is an interest to recognize and exploit anti-oxidative compounds in many natural sources, In fact, seaweeds and their different extracts have confirmed strong antioxidant activity (Yuan and Walsh, 2006).

\footnotetext{
* Corresponding Author

Sivaraman Jayanthi, Plant Biotechnology Division School of Bio Sciences and Technology VIT University Vellore - 632014 Tamil Nadu, India.Email: jayanthi.s@vit.ac.in
}

Proteins with antioxidative properties, phenolic compounds, such as flavonoids and coumarins, tocopherols, nitrogen containing compounds including alkaloids, chlorophyll derivatives, amino acids and amines, as well as other compounds like carotenoids, ascorbic acid, glutathione and uric acid, are powerful antioxidant molecules found in macro algae (Celikler et al., 2009). Several of the currently available synthetic antioxidants exhibiting toxicity, and this necessitates searching for novel, effective and nontoxic antioxidants compounds from natural sources. There are reports in the literature on the antioxidant ability of algae. However, reports are limited for algal glycoproteins having antioxidant properties. The present study aims to determine the antioxidant potential of the purified glycoproteins from $C$. decorticatum. In order to assess the antioxidant potential of GLP, antiradical activities were characterized by different biochemical methods, namely by evaluating their 2,2-diphenyl-1-picrylhydrazyl radical (DPPH), Hydroxyl $(\mathrm{OH})$ radical, superoxide radical $\left(\mathrm{O}_{2}\right)$ and nitric oxide (NO) scavenging abilities. To the best of our knowledge, this is the first report on glycoproteins of $C$. decorticatum.

\section{MATERIALS AND METHODS}

The collection of fresh and healthy specimen of $C$. decorticatum green seaweeds was made between December 2013 and January 2014 during low tide at the depth of 1-3 $\mathrm{m}$ along the coast of Kilakarai, Gulf of Mannar, Tamil Nadu, India. All the 
experimental conditions for extraction and purification of the glycoprotein (GLP) were followed as per our previous study (Thangam et al., 2014). The purified GLP was dialyzed and lyophilized for further in vitro antioxidant analysis.

\section{Free radical scavenging activity}

The $\mathrm{DPPH}^{*}$ (2,2-diphenyl-1-picrylhydrazyl) free radical scavenging activity of purified GLP from Codium decorticatum was determined (Spector et al., 1998 and Suresh et al., 2013). A solution of $0.15 \mathrm{mM}$ ethanolic DPPH* was prepared. About 0.1 $\mathrm{mL}$ of each sample (with the appropriate dilution) was added to $3.0 \mathrm{~mL}$ of ethanolic $\mathrm{DPPH}^{*}$ solution. Discolorations were measured with a proper blank at $517 \mathrm{~nm}$ after incubation for 30 $\min$ at $30{ }^{\circ} \mathrm{C}$ in the dark. Measurements were performed in triplicate. The percentage of DPPH* scavenged was calculated using the following formula:

$$
\mathrm{DPPH}^{*} \text { Scavenging }(\%)=\frac{1-A_{\text {sample }}-A_{\text {blank }}}{A_{\text {control }}} \times 100
$$

where A control is the absorbance of the DPPH* solution without addition of the sample or taken as positive control, A blank is the absorbance of the sample without DPPH* solution, and A sample is the absorbance of the incubation mixture containing both the sample and $\mathrm{DPPH}^{*}$ solution

\section{Hydroxyl radical scavenging activity}

The hydroxyl radical scavenging of purified GLP was investigated using Fenton's reaction $\left(\mathrm{Fe}_{2}++\mathrm{H}_{2} \mathrm{O}_{2} \rightarrow \mathrm{Fe}_{3}++\mathrm{OH}^{-}\right.$ $+\mathrm{OH} \bullet$ ) according to Leong et al., 2002 method. Hydroxyl radicals were generated using $3 \mathrm{~mL}$ of sodium phosphate buffer $(150 \mathrm{mM}$, pH 7.4), which contained $10 \mathrm{mM} \mathrm{FeSO}{ }_{4} \cdot 7 \mathrm{H}_{2} \mathrm{O}, 10 \mathrm{mM}$ EDTA, 2 $\mathrm{mM}$ sodium salicylate, $30 \% \quad \mathrm{H}_{2} \mathrm{O}_{2}(200 \mathrm{~mL})$ and varying concentrations of purified GLP. In control, sodium phosphate buffer was replaced with $\mathrm{H}_{2} \mathrm{O}_{2}$. The solutions were incubated at $37^{\circ} \mathrm{C}$ for $1 \mathrm{~h}$, and the presence of the hydroxyl radical was detected by monitoring the absorbance at $510 \mathrm{~nm}$. Gallic acid was used as the positive control.

\section{Superoxide radical scavenging activity}

The superoxide radical scavenging activity assay was performed based on the ability of purified GLP to inhibit the photochemical reduction of nitro-blue tetrazolium (NBT) in the riboflavin-light-NBT system as described previously by Costa et al., 2010. About $3 \mathrm{~mL}$ of each reaction mixture contained $50 \mathrm{mM}$ phosphate buffer ( $\mathrm{pH}$ 7.8), $13 \mathrm{mM}$ methionine, $2 \mathrm{mM}$ riboflavin, $100 \mathrm{mM}$ EDTA, $75 \mathrm{mM}$ NBT and $1 \mathrm{~mL}$ sample solution. After the formation of blue formosan, the increase in absorbance was measured at $560 \mathrm{~nm}$. The entire reaction assembly was enclosed in a box lined with aluminum foil. The identical tubes with the reaction mixture which served as blanks were kept in the dark conditions. Gallic acid was used as positive control.

\section{Nitric oxide (NO•) radical scavenging activity}

Nitric oxide generated from sodium nitroprusside was measured (Nitha et al., 2010). The 5mM of sodium nitroprusside was mixed with $1 \mathrm{ml}$ of the purified GLP different concentration $(1-5 \mathrm{mg} / \mathrm{mL})$ in phosphate buffer $(\mathrm{pH}$ 7.4). The mixture was incubated at $25^{\circ} \mathrm{C}$ for $150 \mathrm{~min}$. About $0.5 \mathrm{ml}$ of the incubated solution was added with $0.5 \mathrm{~mL}$ of Griess Reagent $(1 \%$ sulfanilamide, $2 \%$ o-phosphoric acid and $0.1 \%$ naphthylethylenediamine dihydrochloride). The absorbance was measured at $546 \mathrm{~nm}$ and galic acid used as positive control. The inhibition of nitric oxide generation was estimated and the scavenging activity was calculated from the same equation that was used to calculate DPPH scavenging activity.

\section{Statistical analysis}

All the experiments were done in triplicates, and the experiments were repeated at least thrice. The statistical software SPSS version 17.0 was used for the analysis. $p$ values were determined using the $\mathrm{t}$ test; $\mathrm{p}$ value $\leq 0.05$ was considered significant.

\section{RESULTS AND DISCUSSION}

Recently our group reported that the extraction and purification of glycoprotein (GLP) with a molecular mass of $\sim 48$ $\mathrm{kDa}$ from $C$. decorticatum. The purified fraction was confirmed in the SDS-PAGE of Periodic acid-Schiff (PAS) staining that the detected protein is a glycoprotein. The yield of the purified GLP was found to be $195 \mathrm{mg}(0.13 \%)$ from $150 \mathrm{~g}$ of dried extract of $C$. decorticatum, and the contents of carbohydrate and protein in GLP were found to be 36.24 and $63.76 \%$, respectively. (Thangam et al., 2014)

Free radicals are highly reactive molecules with an unpaired electron and are produced by byproducts of metabolic processes or radiation. They initiate sequence reactions, which lead to the degeneration of cell membranes and cell compounds, including proteins, lipids and nucleic acids. In addition free radicals are the major reason of food deterioration through lipid oxidation, which finally affects the organoleptic properties and edibility of foods. Hence, the use of an antioxidant may have a therapeutic effect and maintain the freshness of food products. Free radicals scavenge through antioxidants such as lipid peroxyl or peroxide, peroxide, thus reducing the level of oxidative stress and slowing or preventing the development of complications associated with oxidative stress related diseases ( $\mathrm{Wu}$ and Hansen et al., 2008; Suresh et al., 2013).

\section{Free radical scavenging activity}

The scavenging DPPH radicals, hydroxyl radical, superoxide radical and nitric oxide radical activity of the studied GLP are represented in Tables 1. In this work, the DPPH scavenging activities of GLP from $C$. decorticatum marine macro algae were measured (Table 1). The results demonstrated that their degradation fragments all exhibited dose-dependent DPPH scavenging capacities at concentrations ranging from 1.0 to 5.0 $\mathrm{mg} / \mathrm{mL}$. Moreover, the scavenging effects were directly proportional to the concentration of the GLP. The total DPPH 
scavenging effects of the GLP were depicted in Fig. 1. The radical scavenging activities increased significantly $(\mathrm{p}<0.05)$ for samples. DPPH radicals encounter a proton-donating substance such as an antioxidant, the radicals would be scavenged and the absorbance is reduced (Jao and Ko, 2002). The differences in the radical scavenging ability found here might be attributed to the glycan part or protein part or both parts are the reason.

\section{Hydroxyl (OH) radical scavenging activity}

Hydroxyl radical scavenging is well known that the radical system used for antioxidant evaluation might be influence the experimental results and two or more radical systems are required to investigate the radical-scavenging capacities of some antioxidant ( $\mathrm{Yu}$ et al., 2002). The hydroxyl radical-scavenging capabilities of different concentrations of glycoprotein from Codium decorticatum are shown in Fig. 1 and Table 1.

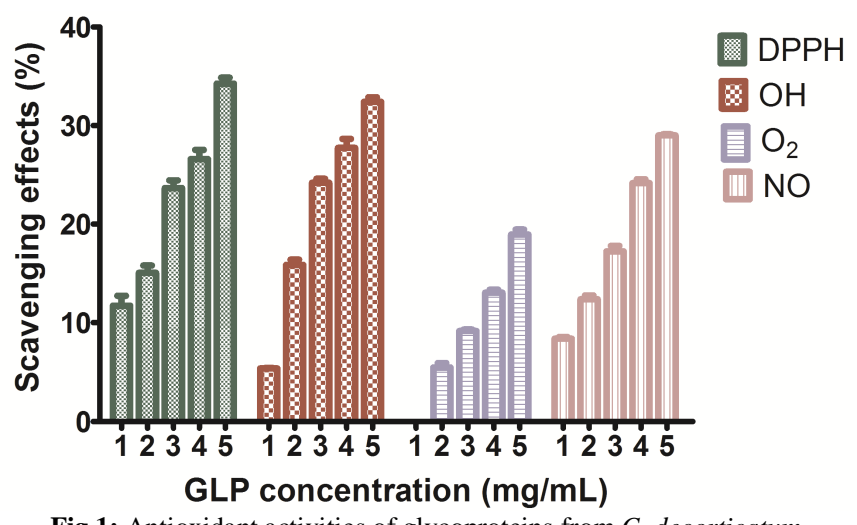

Fig.1: Antioxidant activities of glycoproteins from $C$. decorticatum

All the different concentrations showed relatively good hydroxyl radical-scavenging activity. Hydroxyl radical is the most reactive free radical from superoxide anion and hydrogen peroxide, in the presence of metal-ions, such as copper or iron. The hydroxyl radical reacts with aromatic compounds, can be add on across a double bond, resulting in hydroxylcyclohexadienyl radical. The resulting radical can undergo further reactions, such as reaction with oxygen, to give peroxyl radical, or decompose to phenoxyl-type radicals by water elimination (Lee et al., 2004). The finding in this study revealed that the purified glycoproteins may have some aromatic amino acid that reacting and leading to the reaction.

\section{Superoxide radical scavenging activity}

The superoxide radical was a highly toxic species that was generated in a system of PMS/NADH for the reduction of NBT. The scavenging ability of samples on superoxide radicals were shown significant in a concentration-dependent manner (Table 1). The concentration of the scavenging effect significantly increased with increasing concentration. At a concentration 5.0 $\mathrm{mg} / \mathrm{mL}$, the inhibitory effect of GLP was $18.1 \pm 0.42$.

\section{Nitric oxide (NO•) radical scavenging activity}

Nitric oxide is involved in many physiological processes, such as blood pressure control, neural signal transduction, platelet function and antimicrobial defense (Furchgott, 1999; Ignarro, 1999). Even though the beneficial effects, an overproduction of this reactive species is associated with several types of biological damage (Beckman, 1996). The scavenging activity of the GLP against nitric oxide released by sodium nitroprusside was investigated.

The purified glycoprotein GLP showed quite similar protective activity against nitric oxide, which was concentration dependent as shown in Fig. 1 and Table 1. The standard compound ascorbic acid used in the present study.

We have recently reported about GLP from Codium decorticatum have potential anticancer properties particularly on MDA-MB-231 breast cancer cell lines (Thangam et al., 2014). In 2010 Valentao et al., reported that Codium tomentosum has a potent antioxidant activity.

Interestingly in this study reporting that GLP from $C$. decorticatum have antioxidant properties confirmed by various scavenging activities such as DPPH radical scavenging, hydroxyl radical scavenging, superoxide radical scavenging and nitric oxide radical scavenging assays could be attributed to presence of antioxidant compounds.

Table 1: Free radical, hydroxyl, superoxide radical and nitric oxide radical scavenging activity of glycoprotein from Codium decorticatum. Each value is the mean \pm SD of three determinations and different concentration of the same glycoprotein (GLP).

\begin{tabular}{|c|c|c|c|c|c|}
\hline \multirow{2}{*}{ Sample } & \multirow{2}{*}{ Concentration (mg/mL) } & \multicolumn{4}{|c|}{ Scavenging effects (\%) } \\
\hline & & DPPH & $\mathbf{O H}$ & $\mathbf{O}_{2}$ & NO \\
\hline \multirow{5}{*}{ Purified glycoprotein (GLP) } & 1.0 & $11.73 \pm 1.21$ & $5.3 \pm 0.53$ & $0 \pm 0$ & $7.91 \pm 0.31$ \\
\hline & 2.0 & $15.30 \pm 0.27$ & $15.8 \pm 0.91$ & $5.0 \pm 0.72$ & $11.23 \pm 0.62$ \\
\hline & 3.0 & $23.87 \pm 1.03$ & $23.0 \pm 0.53$ & $9.0 \pm 0.15$ & $15.34 \pm 0.94$ \\
\hline & 4.0 & $26.41 \pm 0.56$ & $26.2 \pm 1.87$ & $12.2 \pm 1.21$ & $22.52 \pm 0.99$ \\
\hline & 5.0 & $33.94 \pm 0.28$ & $31.8 \pm 0.25$ & $18.1 \pm 0.42$ & $27.43 \pm 0.78$ \\
\hline \multirow{5}{*}{ Gallic acid } & 0.05 & $19.6 \pm 1.11$ & $11.6 \pm 1.72$ & $28.9 \pm 0.86$ & $10.8 \pm 0.22$ \\
\hline & 0.10 & $33.6 \pm 0.44$ & $43.6 \pm 0.44$ & $41.8 \pm 0.74$ & $27.1 \pm 0.95$ \\
\hline & 0.25 & $74.3 \pm 0.42$ & $64.3 \pm 0.78$ & $72.1 \pm 0.93$ & $42.5 \pm 0.52$ \\
\hline & 0.50 & $96.7 \pm 1.24$ & $93.7 \pm 0.73$ & $86.3 \pm 0.19$ & $66.7 \pm 0.83$ \\
\hline & 1.0 & $99.0 \pm 0.29$ & $99.0 \pm 0.24$ & $99.0 \pm 0.45$ & $92.1 \pm 0.82$ \\
\hline
\end{tabular}




\section{CONCLUSION}

The results clearly demonstrated that purified glycoproteins (GLP) fractions extracted from C. decorticatum were antioxidative. However, the antioxidant ability of GLP was somewhat different. GLP were stronger antioxidant when the increasing the dose concentration. Moreover, the radical scavenging ability/ some aromatic amino acid present in the glycoproteins which was applicable in the future experiments understanding the relationship between chemical property of GLP and its antioxidant activity. Furthermore which part of GLP is responsible for antioxidant activity, that glycan or protein or both parts are the interest in the responsible for the biological activity.

\section{CONFLICT OF INTEREST STATEMENT}

We declare that we have no conflict of interest.

\section{ACKNOWLEDGEMENTS}

The authors thank the management of VIT University, Vellore for providing their facilities to carry out this work.

\section{REFERENCES}

Athukorala Y, Lee KW, Kim SK, Jeon YJ. Anticoagulant activity of marine green and brown algae collected from Jeju Island in Korea. Bioresour Technol., 2007; 98:1711-1716.

Beckman JS. Oxidative damage and tyrosine nitration from peroxynitrite. Chem. Res. Toxicol., 1996; 9:836-844.

Celikler S, Vatan O, Yildiz G, Bilaloglu R. Evaluation of antioxidative, genotoxic and antigenotoxic potency of Codium tomentosum Stackhouse ethanolic extract in human lymphocyte in vitro. Food Chem Toxicol., 2009; 47:796-801.

Chang HW, Jang KH, Lee D, Kang HR, Kim TY, Lee BH, et al., Monoglycerides from the brown algae Sargassum sagamianum: isolation, synthesis, and biological activity. Bioorg Med Chem Lett., 2008; 1812:3589-3592

Costa LS, Fidelis GP, Cordeiro SL, Oliveira RM, Sabry DA, Camara RBG, et al., Biological activities of sulfated polysaccharides from tropical seaweeds. Biomed Pharmacother., 2010; 64:21-28.

Dias PF, Siqueira JM, Vendruscolo LF, Neiva TDJ, Gagliardi AR, Maraschin M. Antiangiogenic and antitumoral properties of a polysaccharide isolated from the seaweed Sargassum stenophyllum. Cancer Chemother Pharmacol., 2005; 56:436-446.

Furchgott RF. Endothelium derived relaxing factor: Discovery, early studies, and identification as nitric oxide. Bioscience Reports., 1999; 19:235-251.

Ignarro LJ. Nitric oxide: A unique endogenous signalling molecule in vascular biology. Angewandte Chemie International Edition, 1999; 38:1882-1892.
Jao CL, Ko WC. 1,1-Diphenyl-2-picrylhydrazyl (DPPH) radical scavenging by protein hydrolysates from tuna cooking juice. Fish Sci., 2002; 68: 430-435

Lee J, Koo N, Min DB. Reactive oxygen species, aging and antioxidant nutraceuticals. Compreh. Rev Food Sci Food Safety., 2004; 3: 21-33.

Leong LP, Shui G. An investigation of the antioxidant capacity of fruits in Singapore markets. Food Chem., 2002; 76:69-75.

Nitha B, Adhikari SK, Devasagayam TPA, Janardhanan KK. Evaluation of free radical scavenging activity of morel mushroom, Morchella esculenta mycelia: A potential source of therapeutically useful antioxidants. Pharm. Biol., 2010; 48:453-460.

Spector DL, Goldman RD, Leinwand LA. Cells. A Laboratory Manual, vol. 1, Cold Spring Harbor Laboratory Press, New York, 1998 (Chapter 15).

Suresh V, Anbazhagan C, Thangam R, Senthilkumar D, Senthilkumar N, Kannan S, et al., Stabilization of mitochondrial and microsomal function of fucoidan from Sargassum plagiophyllum in diethylnitrosamine induced hepatocarcinogenesis. Carbohydr Polym., 2013: $92: 1377-1385$

Suresh V, SenthilKumar N, Thangam R, Rajkumar M, Anbazhagan C. et al., Process Biochemistry., 2013; 48:364-373.

Thangam R, Senthilkumar D, Suresh V, Sathuvan M, Sivasubramanian S, Pazhanichamy K. et al., Induction of ROS- dependent mitochondria mediated intrinsic apoptosis in MDA-MB-231 cells by glycoprotein from Codium decorticatum. J Agric Food Chemis., 2014; 62:3410-3421.

Valentao P, Pedro T, Daniela G, Paula GDP, Teresa M, Paula AB. Codium tomentosum and Plocamium cartilagineum: Chemistry and antioxidant potential. Food Chemis., 2010 119:1359-1368.

Wu XJ, Hansen C. Antioxidant capacity, phenolic content, polysaccharide content of Lentinus edodes grown in whey permeate-based submerged culture. J Food Sci., 2008; 73:1-8.

Yu L, Haley S, Perret J, Harris M, Wilson J, Qian M. Free radical scavenging properties of wheat extracts. J Agricult Food Chem., 2002; 50: 1619-1624.

Yuan YV, Walsh NA. Antioxidant and antiproliferative activities of extracts from a variety of edible seaweeds. Food Chem Toxicol., 2006; 44: 1144-1150.

Zhou J, Hu N, Wu YL, Pan YJ, Sun CR. Preliminary studies on the chemical characterization and antioxidant properties of acidic polysaccharides from Sargassum fusiforme. J Zhejiang Univ Sci., 2008; 9:721-727.

Zhu W, Chiu LC, Ooi VE, Chan PK, Ang PO. Antiviral property and mechanisms of a SP from the brown alga Sargassum patens against Herpes simplex virus type 1. Phytomedicine, 2006; 13:695-701.

\section{How to cite this article:}

Senthilkumar D, Jayanthi S. Antioxidant activities of purified glycoprotein extracted from Codium decorticatum. J App Pharm Sci, 2015; 5 (12): 101-104. 